\title{
Tyrnilajikkeet Suomen oloihin
}

\author{
Saila Karhu ${ }^{1)}$ ja Soile Prokkola ${ }^{2)}$ \\ ${ }^{1)}$ MTT puutarhatuotanto, Toivonlinnantie 518,21500 Piikkiö, saila.karhu@mtt.fi \\ ${ }^{2)}$ MTT Pohjois-Pohjanmaan tutkimusasema, Tutkimusasemantie 15,92400Ruukki, soile.prokkola@mtt.fi
}

\begin{abstract}
Johdanto
Tyrni (Hippophaë rhamnoides L.) on Suomessa läntisellä rannikolla ja saaristossa esiintyvä luonnonvarainen pensas. Tyrni on hyvin monimuotoinen laji läpi esiintymisalueensa Euraasiassa ja jaettu useaksi alalajiksi (Rousi 1971). Itämeren alueella, siis myös Suomessa, esiintyvä tyrni kuuluu alalajiin $H$. rhamnoides subsp. rhamnoides. Tyrnin emikasveihin kehittyvät marjat, oikeammin pohjushedelmät, ovat tunnettuja korkeasta C-vitamiinipitoisuudestaan sekä moninaisista ravitsemuksellisista ja terveysvaikutuksistaan (Beveridge ym. 1999, Häkkinen ym. 1999, Yang 2001). Laji esiintyy luonnonvaraisena yleensä vain paikallisesti ja vaikeakulkuisilla alueilla. Niinpä tyrnin viljely pelto-oloissa on yleistynyt monissa maissa (Li \& Schroeder 1996) kuten myös Suomessa, jossa sitä vuonna 2002 viljeltiin noin 190 ha alalla (Maa- ja metsätalousministeriön tietopalvelukeskus 2003).

Tyrni on yksi niistä viljelykasveista, jonka viljely- ja käyttömahdollisuuksia ei ole täysin vielä hyödynnetty. Osaltaan tämä on johtunut sopivien viljelylajikkeiden puuttumisesta. Maa- ja elintarviketalouden tutkimuskeskuksessa (MTT) haasteeseen on vastattu lajikejalostuksella. Tyrnin jalostusohjelmien tavoitteena on ollut kehittää lajikkeita, jotka soveltuvat viljelyyn pohjoisissa, vaihtelevissa viljelyoloissamme.
\end{abstract}

\section{Jalostusaineistot ja niiden testaus}

\section{Maan eri osissa 1990-luvulla testatut jalostusaineistot}

Jalostusaineistojen kehittäminen perustui risteytysjalostukseen. Osa siementaimista oli peräisin risteytyksistä, joissa suomalaisten ja joko saksalaisten tyrnien (H. rhamnoides subsp. rhamnoides ) tai Kaukasuksen alueen tyrnikantojen (H. rhamnoides subsp. caucasica) risteymiä risteytettiin keskenään tai venäläisten, Altain alueelta peräisin olevien niin sanottujen siperialaisten lajikkeiden ( $H$. rhamnoides subsp. mongolica) kanssa. Testatut vapaapölytyssiementaimet kasvatettiin seitsemän siperialaisen lajikkeen, Bashkaus, Dar Katuni, Kudyrga, Maslichnaja, Novost Altaja, Vitaminnaja and Zolotoi Pochatok, siemenistä.

Jalostusohjelmassa testattiin myös aiemmista siementaimiaineistoista valittuja ja kloonattuja jalosteita. Jalosteet olivat suomalaisten ja joko Saksan, Kaukasuksen tai Sveitsin alueen tyrnin $(H$. rhamnoides subsp. fluviatilis) luonnonkantojen risteymiä. Testattavana oli myös siemenvaiheessa 5008000 röntgenin sädetyskäsittelyn saaneesta suomalaisen luonnonkannan jälkeläistöstä valittuja jalosteita, muita luonnonkantoja sekä lajikkeet, joista vapaasti pölyttyneet siemenet oli kerätty.

Risteytykset tehtiin Varsinais-Suomessa MTT puutarhatuotannon tutkimusalalla Piikkiössä $\left(60^{\circ} 23^{\prime} \mathrm{N}, 22^{\circ} 33^{\prime} \mathrm{E}\right)$, ja jalosteeet oli valittu siellä aiemin kasvaneesta siementaimiaineistosta (Junnila \& Hiirsalmi 1989). Taimiaineistoa havainnoitiin MTT:n tutkimusasemilla: merellisemässä ilmastossa etelässä Kokemäellä Satakunnassa $\left(61^{\circ} 16^{\prime} \mathrm{N}, 22^{\circ} 15^{\prime} \mathrm{E}\right)$ ja pohjoisessa Ruukissa Pohjois-Pohjanmaalla $\left(64^{\circ} 41^{\prime} \mathrm{N}, 25^{\circ} 05^{\prime} \mathrm{E}\right)$ sekä mantereisemmalla alueella pohjoisessa Sotkamossa Kainuussa $\left(64^{\circ} 06^{\prime} \mathrm{N}\right.$, $\left.28^{\circ} 20^{\prime} \mathrm{E}\right)$.

Kasveista havainnoitiin vuosina 1990-1997 useita kasvullisia, fenolologisia ja sato-ominaisuuksia. Kaikista emijalosteista ja joistakin siementaimista määritettiin marjojen C-vitamiinipitoisuudet (Karhu \& Ulvinen 1999).

\section{Pohjois-Pohjanmaalla testatut uudet jalostusaineistot}

MTT:n Pohjois-Pohjanmaan tutkimusasemalla aloitettiin uusi jalostusohjelma 1990-luvun lopulla tavoitteena kehittää paikallisiin oloihin soveltuvia, helposti poimittavia lajikkeita ammattiviljelyyn.

Osa jälkeläistöistä oli peräisin 23 erilaisesta kontrolloidusti tehdystä risteytyksestä. Pölyttäjinä käytettiin useimmiten Raahen alueen luonnonvaraisia hedekantoja. Emikasveina risteytyksissä käytettiin edellä kuvatun vanhemman jalostusaineiston kasveja, Moskovan yliopistossa jalostettuja lajikkeita Finskaja, Gibrid Pertsika (Hybrid Pertsika), Kaliningradskaja ja Moskovskaja, siperialaisia lajikkeita 
Obilnaja ja Oranzevaja sekä paikallisilla viljelmillä menestyneitä tuntemattomia lajikkeita.

Osa siementaimista oli peräisin vapaapölytyksistä, joissa siemenet kerättiin paikallisesti pitkäaikaisessa viljelyssä menestyneistä Pohjanlahden pohjoisosan luonnonkannoista, vanhemman jalostusaineiston kasveista sekä lajikkeista Dar Katuni ja Zolotistaja Sibiri. Vapaapölytysjälkeläistöjä oli yhteensä 26.

Siemenet idätettiin vuosina 1998 ja 1999. Koko jalostusaineiston taimimäärä oli noin 9500, ja kesällä 1999 taimia istutettiin tutkimusaseman lisäksi 31 viljelmälle, yhteensä noin 8 ha alalle. Viljelijöiden vastuulle annettiin aineiston hoito ja sadonkorjuu, MTT:n vastuulle jäi muu havainnointi. Jalostusaineistosta havainnoitiin vuosina 2000-2003 talvehtiminen, versolaikkutaudin oireet, pensaiden kasvu ja piikkisyys. Vuosina 2002-2003 vanhimpien taimien alkaessa marjoa havainnoitiin satoon ja sadonkorjuuseen liittyviä ominaisuuksia: marjakoko, marjaperän pituus ja marjan irrottamiseen tarvittava massa. Aineiston havainnointi jatkuu edelleen, ja parhaat yksilöt valitaan lisättäviksi koeviljelyyn.

\section{Aineistojen menestyminen ja ominaisuudet}

\section{0-luvun havaintotulokset maan eri osista}

Taimet kasvoivat istutuksen jälkeen nopeammin eteläisellä kuin pohjoisemmilla koepaikoilla. Eri jalosteiden ja siementaimijälkeläistöjen välillä erot kasvunopeudessa olivat suuret, mutta siementaimijälkeläistöjen kasvu ei eronnut merkitsevästi niiden emolajikkeiden kasvuvauhdista.

Neljä vuotta istutuksen jälkeen kookkaimmat pensaat olivat yli neljä metriä korkeita ja kasvien keskimääräinen korkeus oli etelässä yli kaksi metriä. Pohjoisessa pituuskasvu oli hitaampaa, esimerkiksi Ruukissa kasvit olivat kolmanneksen matalampia kuin Kokemäellä. Kasvien leveydessä erot koepaikkojen välillä olivat pienemmät. Täysin suomalaista alkuperää olevat jalosteet kasvoivat hillitysti; neljän vuoden kuluttua istutuksesta niiden keskimääräinen korkeus oli etelässä 1,5 metriä ja viidenneksen vähemmän pohjoisessa.

Lajikkeiden runsas- tai vähäpiikkisyys periytyi myös niiden jälkeläistöihin. Piikkisyyden määrään vaikutti myös koepaikka siten, että kasvit olivat vähemmän piikkisiä pohjoisilla testipaikoilla.

Pohjoisuus vaikutti myös siihen, minkä ikäisinä taimet saavuttivat hedelmälliseen vaiheen: pohjoisessa se tapahtui myöhemmin kuin etelässä. Eroja oli myös risteytysjälkeläistöjen välillä. Suurin osa muiden siperialaisten lajikkeiden siementaimista kukki viiden vuoden iässä, mutta Bashkaus-, Dar Katuni - ja Vitaminnaya-lajikkeiden jälkeläistöistä pääosa aloitti kukinnan vasta myöhemin. Hedekasveja, joissa oli myös emikukkia, löytyi runsaasti erityisesti pohjoisilta koepaikoilta.

Jo ensimmäisten testivuosien aikana pohjoisessa kuoli enemmän taimia kuin etelässä. Jalostusaineistosta löytyi kuitenkin myös pohjoisilla koepaikoilla hyvin menestyviä genotyyppejä. Pohjoisuuden lisäksi menestymiseen vaikutti ilmastotyyppi: aineistosta kaksi kolmasosaa selviytyi hengissä koko testikauden eteläisessä merellisessä ilmastossa Satakunnassa ja pohjoisessa mantereisemmissa oloissa Kainuussa, kun taas pohjoisen merellisemmissä oloissa Pohjois-Pohjanmaalla vain noin puolet aineistosta säilyi hengissä.

Heikon ilmastollisen sopeutumisen ohella huonon menestymisen syynä oli sienitauti, tyrnin versolaikku (Stigmina sp.), joka ensimmäisen kerran löydettiin Suomesta 1990-luvulla (Parikka \& Karhu 1998, 1999). Versolaikkutaudin voimakkaan esiintymisen takia valintatyössä kiinnitettiin erityisesti huomiota taudinkestoon. Siperialaiset lajikkeet osoittautuivat aroiksi tälle taudille ja alttius periytyi myös jälkeläistöihin.

Suomalaiset luonnonkannat osoittautuivat versolaikkutaudille hyvin kestäviksi. Kotimaisten tyrnikantojen taudinkestävyys näkyi myös näiden jälkeläistöissä. Saksalaista ja kaukasuslaista alkuperää olevat tyrnit eivät ilmastollisesti sopeutuneet pohjoisimmille koepaikoille, ja Kaukasuksen alueen tyrnikanta kärsi kohtalaisesti myös versolaikkutaudista.

Jalostusaineiston marjojen C-vitamiinipitoisuuksissa oli suurta vaihtelua, jopa samasta risteytyksestä peräisin olevan siementaimiaineiston sisällä. Jalosteissa, joissa oli Itämeren alueen tai sveitsiläisen tyrnin perimää, C-vitamiinipitoisuus oli korkeampi kuin niissä, jotka periytyivät kaukasuslaisista tai siperialaisista alkuperistä (Karhu \& Ulvinen 1999).

Vuosien 1996-1997 voimakkaan versolaikkuepidemian jälkeen suurin osa siementaimiaineistosta päätettiin jättää pois ja vain muutama valittiin edelleen testattavaksi. Kolme taudinkestävää kotimaiseen tyrnikantaan perustuvaa jalostekloonia nimettiin lajikkeeksi vuonna 2000 (Karhu 2000, 2003).

\section{0-luvun ensimmäiset havainnot Pohjois-Pohjanmaalla}


Vuonna 1999 istutetut taimet selvisivät hengissä istutusta seuraavaan vuoteen suotuisan talven ansiosta hyvin, vaikka osa taimista oli istutettaessa erittäin pieniä. Myöhemmät havainnot osoittivat, että mitä enemmän perimässä oli siperialaisten tyrnien perimää, sitä enemmän ne kärsivät talvivaurioista ja versolaikkutaudista ja sitä suurempi niiden kuolleisuus oli (Prokkola 2003a). Venäläisten tyrnilajikkeiden heikko menestyminen täkäläisissä oloissa tuli ilmi myös 1990-lopussa Pohjois-Pohjanmaan tutkimusasemalle perustetussa lajikekokeessa, kun Moskovan yliopistossa jalostetut lajikkeet kärsivät pahoin talvista ja versolaikkutaudista (Prokkola 2003b).

Kesällä 2002 satohavainnot voitiin tehdä jalostusaineistossa 144 marjovasta pensaasta. Luonnonkannoista periytyvistä kasveista oli tällöin vasta muutama satoiässä. Marjan irrottamiseen tarvittava massa vaihteli välillä $132-454 \mathrm{~g}$. Myös marjakoko, marjaperän pituus ja piikkisyys vaihtelivat suuresti. Sato-ominaisuuksien välillä ei ollut mainittavia korrelaatioita (Prokkola 2003a).

\section{Varhemman jalostusohjelman tulos: uudet lajikkeet}

1990-luvulla havainnoiduista jalosteklooneista laskettiin kauppaan emilajikkeet Terhi ja Tytti ja hedelajike Tarmo (Karhu 2000, 2003). Ne ovat kaikki samaa alkuperää, kehittyneet siemenistä, jotka on kerätty MTT puutarhatuotannon koekentällä Piikkiössä kasvaneesta kotimaisesta luonnonkannasta. Ennen idätystä siemeniä on käsitelty 1000-2000 röntgenin sädetyksellä. Kaikki lajikkeet ovat osoittaneet hyvää tyrnin versolaikkutaudin kestävyyttä ja ilmastollista sopeutumista eri koepaikoilla. Emilajikkeet ovat hillittykasvuisia, kun taas Tarmo-lajike on melko voimakaskasvuinen.

Emilajikkeiden marjat ovat vanhemman suomalaisen Raisa-lajikkeen marjoja noin kaksi kertaa suuremmat, niiden massa on 0,4-0,5 grammaa. Marjat kiinnittyvät lyhyellä, noin $2 \mathrm{~mm}$ marjaperällä tiukasti kiinni oksiin. Täysikasvuisten emipensaiden sato on vaihdellut välillä 4-12 kg. Marjat ovat kirpeitä, sillä niiden sokeripitoisuus on matala ja happopitoisuus korkea. Marjojen C-vitamiinipitoisuus on korkea, Tytti-lajikkeella on mitattu jopa $300 \mathrm{mg} / 100 \mathrm{~g}$ ylittäviä arvoja.

Lajikkeita voidaan lisätä kesäpistokkaista. Pistokkaiden juurtuminen onnistuu parhaiten käyttämällä apuna auksiinia (esimerkiksi indoli-3-voihappo, IBA).

\section{Johtopäätökset}

Havaittu suuri vaihtelu siementaimien ominaisuuksissa luo hyvät edellytykset sille, että risteytysjalostusta voidaan hyödyntää tyrnilajikkeiden jalostuksessa. Heikko korrelaatio joidenkin sato-ominaisuuksien välillä lisää mahdollisuuksia helposti poimittavan lajikkeen kehittämisessä.

Itä- ja Keski-Euroopasta sekä Aasian alueelta peräisin olevia tyrnejä voidaan lajikejalostuksessa käyttää hyväksi lisäämään jälkeläistöihin useita hyödyllisiä ominaisuuksia, kuten kasvuvoimakkuutta, aikaista satoikää, piikittömyyttä ja marjakokoa. Suomalaisten tyrnilajikkeiden jalostuksessa aineiston luomisessa kannattaa kuitenkin aina käyttää myös täkäläisiä, perimältään meidän ilmastollisiin oloihimme sopeutuneita ja tyrnin versolaikkutautia kestäviä kantoja.

\section{Kirjallisuus}

Beveridge, T., Li, T.S.C., Oomah, B.D. \& Smith, A. 1999. Sea buckthorn products: Manufacture and composition. J. Agric. Food Chem. 47: 3480-3488.

Häkkinen, S.H., Kärenlampi, S.O., Heinonen, I.M., Mykkänen, H.M. \& Törrönen, A.R. 1999. Content of the flavonols quercetin, myricetin, and kaempferol in 25 edible berries. J. Agric. Food Chem. 47: 2274-2279.

Junnila, S. \& Hiirsalmi, H. 1989. Breeding and cultural research of sea buckthorn in northern conditions. Proceedings of International Symposium on Sea Buckthorn (H.rhamnoides L.). Xian, China. p.215-216.

Karhu, S. 2000. Odotetut uutuudet: Testatusti kestävät tyrnit. Puutarha \& kauppa 4, 37: 6-7.

Karhu, S. 2003. Uudet tyrnilajikkeet Terhi, Tytti ja Tarmo. Julkaisussa: Sadonkorjuu, Tutkittua puutarhatuotantoa 2000-2002. MTT:n selvityksiä 42: 38-39. Toim. T. Hovi, S. Karhu, M.-M. Linna \& T. Suojala. Viitattu 3.12.2003. Julkaistu 1.8.2003. Saatavilla Internetissä: http://www.mtt.fi/mtts/pdf/mtts42.pdf.

Karhu, S.T. \& Ulvinen, S.K. 1999 Vitamin C: A variable quality factor in sea buckthorn breeding. Julkaisussa: Agri-Food Quality II. Quality Management of Fruit and Vegetables. Cambridge, The Royal Society of Chemistry. p. 360-362. Toim. M. Hägg, R. Ahvenainen, A.-M. Evers \& K. Tiilikkala. ISBN 0-85404-788-3.

Li, T.S.C. \& Schroeder, W.R. 1996. Sea buckthorn (Hippophä rhamnoides L.): A multipurpose plant. HortTechnology 6: 370-380.

Maa- ja metsätalousministeriön tietopalvelukeskus. 2003. Maataloustilastoja [verkkojulkaisu]. Viitattu 3.12.2003. Saatavilla Internetissä: http://tike.mmm.fi/Tilasto/pure_marja_hed_avomaalla.pdf.

Parikka, P. \& Karhu, S. 1998. Stem canker on sea buckthorn (Hippophae rhamnoides) in Finland. ICPP $-7^{\text {th }}$ 
International Congress of Plant Pathology, Ediburgh, Scotland. Offered papers, vol. 3, abstract 3.7.51. 1 p.

Parikka, P. \& Karhu, S. 1999. Versolaikku vaivaa tyrniä. Puutarha \& kauppa 3, 1: 8.

Prokkola, S. 2003a. Breeding of sea buckthorn cultivars for North Ostrobothnia. Julkaisussa: Proceedings of the NJF's 22nd congress 'Nordic Agriculture in Global Perspective', July 1-4, 2003, Turku, Finland. p. 238. Toim. O. Niemeläinen \& M. Topi-Hulmi. Viitattu 3.12.2003. Julkaistu 15.9.2003. Saatavilla Internetissä: http://portal.mtt.fi/pls/portal30/docs/folder/agronet/yhteiset_hankkeet/njf/njf2003/14.pdf.

Prokkola, S. 2003b. Reliability of Russian cultivars in North Ostrobothnia, Finland. Acta Hort. 626: 389-395. Viitattu 3.12.2003. Saatavilla Internetissä: http://www.actahort.org/books/626/626 54.htm.

Rousi, A. 1971. The genus Hippophaë L: a taxonomy study. Ann. Bot. Fenn. 8: 177-277.

Yang, B. 2001. Lipophilic components of sea buckthorn (Hippophä rhamnoides) seeds and berries and physiological effects of sea buckthorn oils. Academic dissertation on Food Chemistry. University of Turku. ISBN 951-29-2221-5. 